\title{
Detection of mRNA by Whole Mount in situ Hybridization and DNA Extraction for Genotyping of Zebrafish Embryos \\ Rachna Narayanan ${ }^{1,2}$ and Andrew C. Oates ${ }^{1,2,3, *}$
}

\begin{abstract}
${ }^{1}$ Interfaculty Institute of Bioengineering, School of Life Sciences, École Polytechnique Fédérale de Lausanne, Lausanne, Switzerland; ${ }^{2}$ The Francis Crick Institute, London, United Kingdom; ${ }^{3}$ Department of Cell and Developmental Biology, University College London, London, United Kingdom *For correspondence: andrew.oates@epfl.ch
\end{abstract}

[Abstract] In situ hybridization is used to visualize the spatial distribution of gene transcripts in tissues and in embryos, providing important information about disease and development. Current methods involve the use of complementary riboprobes incorporating non-radioactive labels that can be detected by immunohistochemistry and coupled to chromogenic or fluorescent visualization. Although recent fluorescent methods have allowed new capabilities such as single-molecule counting, qualitative chromogenic detection remains important for many applications because of its relative simplicity, low cost and high throughput, and ease of imaging using transmitted light microscopy. A remaining challenge is combining high contrast signals with reliable genotyping after hybridization. Dextran sulfate is commonly added to the hybridization buffer to shorten development times and improve contrast, but this reagent inhibits PCR-based genotyping. This paper describes a modified protocol for in situ hybridization in fixed whole mount zebrafish embryos using digoxigenin (DIG) labeled riboprobes that are detected with alkaline phosphatase conjugated anti-DIG antibodies and nitroblue tetrazolium (NBT)/5-bromo-4-chloro-3-indolyl-phosphate (BCIP) chromogenic substrates. To yield embryos compatible with downstream genotyping after hybridization without sacrificing contrast of the signal, this protocol omits dextran sulfate and utilizes a lower hybridization temperature.

Keywords: In situ, Hybridization, WISH, Zebrafish, Staining, Qualitative assay

[Background] In situ hybridization is a technique that enables the detection of RNA in single cells, tissues or in whole embryos (Schulte-Merker et al., 1992; Hauptmann and Gerster, 1994; Schulte-Merker et al., 1994). The technique has been widely employed in developmental biology to characterize the spatial and temporal distributions of target mRNAs in fixed embryos (Thisse et al., 2001; Thisse and Thisse, 2004 and 2005). By allowing the comparison of mRNA distributions in wild-type, mutant and experimentally manipulated embryos, in situ hybridization continues to play a vital role in the investigation of gene function in development.

Hybridization is based on the principle of complementary base-pair binding of a specific probe oligonucleotide to a target mRNA. RNA oligonucleotides (riboprobes) are designed to pair with target mRNA molecules and are synthesized with nucleotides containing haptens, such as digoxigenin (DIG). In in situ hybridization, the riboprobes are incubated with previously fixed and permeabilized bulk tissue or intact embryos at an elevated temperature to favor the formation of hybrids with high sequence 
complementarity. The stable target-probe hybrids are then detected with a hapten-specific antibody. In chromogenic variations of the technique, the antibody is conjugated to alkaline phosphatase. This enzymatic activity results in the local generation of a colored precipitate upon the addition of a chromogenic substrate. NBT and BCIP are commonly used substrates yielding a purple-blue precipitate. Thus, the localization of target mRNA can be visualized with cellular resolution in the embryo or tissue by a colored signal in transmitted light microscopy.

The technique has been modified to compare the localization of two mRNAs by including different haptens on different probes (Hauptmann and Gerster, 1994) or combined with immunohistochemistry to compare the localization of mRNA and protein. Recent advances allow the fluorescent detection of multiple genes (Choi et al., 2010; Gross-Thebing et al., 2014), the sub-cellular localization of mRNAs (Jambor et al., 2015) and the determination of the number of transcripts in a sample (Wang et al., 2012; Little et al., 2013; Stapel et al., 2016; Trivedi et al., 2018). Nevertheless, qualitative chromogenic detection remains important in the field because of its relative simplicity, low cost, high throughput and ease of imaging.

The signal to noise ratio of the colored signal of an in situ hybridization experiment is a function of the specificity of riboprobe, i.e., the ability of the riboprobe to distinguish between different targets, and the stringency of the hybridization. High stringency requires the base pairing of all bases in the oligonucleotide while lower stringency allows some bases to be unpaired. The design of the riboprobe sets the specificity of hybridization. The reaction environment affects the stringency-annealing of oligonucleotides and the thermal stability of the resulting hybrid is influenced by temperature, $\mathrm{pH}$, the concentration of monovalent cations and the presence of organic solvents in the environment.

Riboprobes have to be designed to be maximally complementary to the target mRNA for high specificity. Additionally, maximally complementary RNA-RNA hybrids have the highest thermal stability as base pair mismatches lower the thermal stability. The length of the riboprobe will affect the hybridization rate and also influence the thermal stability of the resulting hybrid-longer probes have a higher hybridization rate and generate thermally stable hybrids (Wetmur, 1976). Riboprobes of lengths between 300-3,200 base pairs specific to the target can be used with the protocol described here.

The temperature used for hybridization is determined from the melting temperature of the designed oligonucleotide. Hybridization is performed $15-25{ }^{\circ} \mathrm{C}$ lower than the calculated melting temperature (Wetmur and Davidson, 1968)-the higher this temperature, the greater the stringency of hybridization. However, prolonged incubation at typical RNA hybridization temperatures will degrade sample morphology. Therefore, organic solvents are added to reduce the thermal stability of the RNA duplexes, with formamide being the most common reagent (McConaughy et al., 1969). Hybridization buffers used in in situ hybridization also contain monovalent sodium cations, from sodium chloride and sodium citrate, which interact electrostatically with the RNA-RNA hybrid to stabilize it. Low salt washes are subsequently performed to reduce background by preferentially reducing the stability of non-specific hybrids.

Typical in situ protocols for the qualitative detection of mRNA in whole mount in zebrafish recommend a hybridization temperature of $70{ }^{\circ} \mathrm{C}$ (Thisse and Thisse, 2008) for high stringency. Such 
high stringency conditions are necessary if a riboprobe is required to discriminate between two similar target sequences. We found that for riboprobes with high specificity, by performing hybridization at lower temperatures $\left(55-60^{\circ} \mathrm{C}\right)$, we could achieve a more rapidly developing, higher contrast stain. We could further reduce the development time and enhance the contrast of the stain by increasing the effective concentration of riboprobe by adding dextran sulfate to the hybridization buffer (Lauter et al., 2011). Additionally, for probes that required prolonged development, the addition of polyvinyl alcohol to the NBT-BCIP staining solution reduces background (Kiyama and Emson, 1991). Making these modifications to the in situ hybridization protocol consistently accelerates the development and enhances the contrast of the stain.

A key part of an in situ experiment is the qualitative analysis of variations in mRNA distributions in mutant or otherwise experimentally manipulated embryos. However, differences in mRNA distributions may be evident before the genotype of the embryo can be ascertained by altered morphology. Further, such differences can be subtle, or variable, and may not fall into convenient Mendelian ratios complicating a straightforward assignment of wild-type and perturbed patterns. For these reasons, it is valuable to have a protocol compatible with reliable genotyping of embryos, or fragments of embryos, after hybridization and photographic documentation. We have observed that the presence of dextran sulfate in the hybridization buffer inhibits genotyping by PCR; therefore it is omitted if the embryos need to be genotyped after in situ hybridization.

The protocol described here describes three linked procedures: (1) the generation of DIG-labeled riboprobes suitable for hybridization; (2) in situ hybridization using a single riboprobe to qualitatively detect an mRNA target of interest in developing zebrafish embryos and imaging of the embryos; and (3) DNA extraction that gives a PCR-ready extract, enabling the presence or absence of indel mutations to be identified in the genomic DNA of individual, previously imaged embryos. We have successfully tested the protocol in labs in two different countries. Combined, these procedures form a protocol sufficiently detailed to enable a relatively inexperienced experimentalist to achieve high quality and reliable analysis of mRNA distribution patterns with a range of experimental perturbations.

\section{Materials and Reagents}

\section{A. Riboprobe synthesis}

1. $1.5 \mathrm{ml}$ colorless microfuge tubes (Eppendorf, SafeLock, catalog number: 0030120086)

2. PCR tubes (Sarstedt, Multiply ${ }^{\circledR}$ - $\mu$ strip Pro 8-strip, catalog number: 72.991 .002 )

3. Restriction digest enzymes (Thermo Scientific, FastDigest) (store at $-20^{\circ} \mathrm{C}$ )

4. 2x Phusion Hot Start II High-Fidelity PCR Master Mix (Thermo Scientific, catalog number: F-565) (store at $-20^{\circ} \mathrm{C}$ )

5. rNTP-DIG (Roche, catalog number: 11277073910 ) (store at $-20^{\circ} \mathrm{C}$ )

6. RNase Inhibitor (RNaseOUT, Invitrogen, catalog number: 100000840) (store at $-20^{\circ} \mathrm{C}$ )

7. RNA polymerases $(1,000 \mathrm{U}-20 \mathrm{U} / \mu \mathrm{l})$ (store at $-20{ }^{\circ} \mathrm{C}$ )

a. Sp6 (Roche, catalog number: 10810274001) 

b. $\quad$ T3 (Roche, catalog number: 11031163001)
c. $\quad$ T7 (Roche, catalog number: 10881767001)

8. Clean up kits (store at room temperature)
a. Qiaquick PCR purification kit (QIAGEN, catalog number: 28104)
b. Promega SV Gel Wizard PCR purification kit (Promega, catalog number: A9281)
c. RNeasy Min Elute (QIAGEN, catalog number: 74204)

9. Agarose (Sigma-Aldrich, catalog number: A9539) (store at room temperature)

10. $1 x$ Tris-Acetate, EDTA (TAE) (store at room temperature, see Recipes)
a. Tris Base (Sigma-Aldrich, BioXtra, catalog number: T6791) (store at room temperature)
b. Glacial acetic acid (Suprapur ${ }^{\circledR}$, EMD Millipore, catalog number: 1.00066) (store at room temperature)
c. EDTA, $0.5 \mathrm{M}$ (UltraPure, Invitrogen, catalog number: 15575-038) (store at room temperature)

11. Hybridization buffer $(\mathrm{Hyb})$ (store at $-20^{\circ} \mathrm{C}$, see Recipes)
a. Formamide, deionized (Roche, catalog number: 1814320) (store at $4{ }^{\circ} \mathrm{C}$ )
b. $50 \mathrm{mg} / \mathrm{ml}$ Heparin stock (store at $4{ }^{\circ} \mathrm{C}$, see Recipes)
Heparin (Sigma-Aldrich, catalog number: H3400) (store at room temperature)
c. Torula-RNA (Sigma-Aldrich, catalog number: R6875) (store at $-20^{\circ} \mathrm{C}$ )
d. 20x SSC (store at room temperate, see Recipes)
Sodium chloride (Sigma-Aldrich, BioXtra, catalog number: S7653)
Trisodium citrate dihydrate (Sigma-Aldrich, catalog number: C8532) (store at room temperature)
e. (Optional) Dextran sulfate sodium salt (Sigma-Aldrich, catalog number: D6001) (store at $\left.4{ }^{\circ} \mathrm{C}\right)$
f. $10 \%$ Tween-20 (see Recipes)
Tween-20 (Sigma-Aldrich, catalog number: P9416) (store at room temperature)

\section{B. Embryo culture}

1. $94 \mathrm{~mm}$ polystyrene Petri dish (Grenier Bio-One, catalog number: 633161)

2. $100 \times$ PTU stock (store at room temperature, see Recipes)

N-Phenylthiourea (PTU, Sigma-Aldrich, catalog number: P7629) (store at room temperature)

C. In situ hybridization

1. 24-well plates (Grenier Bio-One, Cell Star, catalog number: 662160)

2. $2 \mathrm{ml}$ colorless microfuge tubes (Eppendorf, SafeLock, catalog number: 0030120094)

3. $3 \mathrm{ml}$ plastic non-sterile, macrograduated Pasteur pipettes (HuberLab, catalog number: 15.4051.11)

4. $94 \mathrm{~mm}$ polystyrene Petri dish (Grenier Bio-One, catalog number: 633161)

5. Thin walled plastic container (Microwaveable plastic lunch box-any brand) 
Please cite this article as: Narayanan and Oates, (2019). Detection of mRNA by Whole Mount in situ Hybridization and DNA Extraction for Genotyping of

6. Methanol (Fisher, catalog number: M/4000/15) (store at room temperature)

7. Phosphate buffered saline, $0.1 \%$ Tween (PBST) (store at room temperature, see Recipes)

a. Sodium chloride (Sigma-Aldrich, BioXtra, catalog number: S7653) (store at room temperature)

b. Potassium chloride (Sigma-Aldrich, BioXtra, catalog number: P9333) (store at room temperature)

c. Sodium phosphate dibasic (Sigma-Aldrich, BioXtra, catalog number: S7907) (store at room temperature)

d. Potassium phosphate monobasic (Sigma-Aldrich, catalog number: P9791) (store at room temperature)

e. $10 \%$ Tween-20 (see Recipes)

8. $4 \%$ Paraformaldehyde (PFA) in PBST (store at $4{ }^{\circ} \mathrm{C}$ ) (see Recipes)

a. PFA powder (Sigma-Aldrich, catalog number: P6148) or 16\% PFA (Alfa Aesar, catalog number: $43368.9 \mathrm{M}$ ) (store at $4{ }^{\circ} \mathrm{C}$ )

b. PBST (see Recipes)

9. Proteinase $\mathrm{K}$ stock (store at $-20^{\circ} \mathrm{C}$, see Recipes)

Proteinase K (Merck, catalog number: 1.24568) (store at $4{ }^{\circ} \mathrm{C}$ )

10. Hybridization buffer $(\mathrm{Hyb})$ (store at $-20^{\circ} \mathrm{C}$, see Recipes)

11. Post-hybridization washes (see Recipes)
a. Wash 1
b. Wash 2
c. Wash 3

D. Detection

1. AP-conjugated anti-DIG antibody (Anti-Digoxigenin-AP, Fab fragments from sheep) (Roche, catalog number: 11093274910) (store at $4{ }^{\circ} \mathrm{C}$ )

2. Maleic acid buffer, $0.1 \%$ Tween (MABT) (store at room temperature, see Recipes)
a. Maleic acid (Sigma-Aldrich, catalog number: M0375) (store at room temperature)
b. Sodium chloride (Sigma-Aldrich, BioXtra, catalog number: S7653) (store at room temperature)
c. Sodium hydroxide (Fisher Chemical, catalog number: S/4920/60) (store at room temperature)
d. $10 \%$ Tween-20 (see Recipes)

3. $10 \%$ Blocking reagent in maleic acid buffer
a. Blocking Reagent (Roche, catalog number: 11096176001) (store at room temperature)
b. Maleic acid buffer (see Recipes)

4. $2 \%$ Blocking reagent in MABT ( $2 \%$ Roche block) (see Recipes)

5. Staining buffer (see Recipes)

a. Tris- $\mathrm{HCl}$ (Sigma-Aldrich, BioXtra, catalog number: T6666) (store at room temperature) 
b. Magnesium chloride hexahydrate (Sigma-Aldrich, BioXtra, catalog number: M2670) (store at room temperature)

c. Sodium chloride (Sigma-Aldrich, BioXtra, catalog number: S7653) (store at room temperature)

6. Staining solution (see Recipes)

a. NBT (Roche catalog number: 11383213001 ) (aliquot and store at $-20^{\circ} \mathrm{C}$ )

b. BCIP (Roche, catalog number: 11282221001 ) (aliquot and store at $-20^{\circ} \mathrm{C}$ )

c. Staining buffer (see Recipes)

d. (Optional) Polyvinyl alcohol (PVA, Sigma-Aldrich, catalog number: P1763) (store at room temperature)

E. Mounting

1. $60 \mathrm{~mm}$ Petri dish

2. A human eyelash glued to a tooth pick/syringe needle or a fine pipette tip (GELoader Tips 0.5-20 $\mu \mathrm{l}, 62 \mathrm{~mm}$, Eppendorf, catalog number: 0030001222)

3. (Optional) Mold for embryos for photographic documentation in whole mount [the mold negative is made in our laboratory (Herrgen et al., 2009)]

\section{Materials for flat mounting:}

4. (Optional) Dissection hook (Picker et al., 2009) made with Tungsten wire (Hamilton, catalog number: 18306)

5. $10 \mu$ pipette tip

6. Glass slides (Thermo Scientific, Superfrost, catalog number: 12372098)

7. Glass coverslip (VWR, Menzel Gläser, \#1.5 rectangular $22 \times 40 \mathrm{~mm}$, catalog number: 631-1370)

8. Silicone grease or petroleum jelly (such as Vaseline)

9. Transparent nail varnish (any brand)

10. $87 \%$ glycerol in distilled water (store at room temperature, see Recipes) Glycerol (Fisher, catalog number: G/0650/08) (store at room temperature)

F. Genomic DNA extraction (store at room temperature)

1. $50 x$ base solution (see Recipes)

a. Potassium hydroxide (Fisher Chemical, catalog number: P/5640/60)

b. EDTA, $0.5 \mathrm{M}$ (UltraPure, Invitrogen, catalog number: 15575-038)

2. $1 x$ base solution (see Recipes)

3. 50x neutralization solution (see Recipes)

Tris- $\mathrm{HCl}$ (Sigma-Aldrich, catalog number: T6666)

4. $1 x$ neutralization solution (see Recipes) 


\section{Equipment}

A. Stock solution preparation

1. Magnetic stirrer (Heidolph Instruments, model: MR Hei-Standard, catalog number: 505-20000-00)

2. $\mathrm{pH}$ meter (Mettler Toledo, model: Seven compact and InLab Expert Pro-ISM)

B. Riboprobe synthesis

1. PCR machine (Eppendorf, model: Mastercycler pro S)

2. Thermoblock (Eppendorf, model: ThermoMixer $\mathrm{C}$ and SmartBlock $2.0 \mathrm{ml}$ )

3. Gel electrophoresis (Bio-Rad, model: PowerPac Basic Power Supply; Wide Mini-Sub Cell GT Cell)

4. NanoDrop spectrophotometer (Thermo Fisher, model: NanoDrop ${ }^{\mathrm{TM}}$ 2000, catalog number: ND 2000)

C. In situ hybridization

1. Forceps (Dumont, model: 5-Inox-E)

2. Stereomicroscope (Olympus, model: SZ61)

3. Shaker (Heidolph, model: Duomax1030, catalog number: 543-32205-00)

4. (Optional) Vacuum set-up (Integra, Vacusafe aspiration system)

5. Water bath (GFL, model: 1003)

6. (Optional) Well plate stand (Diversified Biotech, catalog number: WPST-1000)

D. Documentation

1. RGB Camera (Olympus, model: DP22)

2. Ring light (Photonic Optics, model: LED 40 ring light)

E. Genomic DNA extraction

1. Micro knife (Fine Science Tools, catalog number: 10315-12)

\section{Software}

1. Fiji (Schindelin et al., 2012, https://fiji.sc/)

2. Snapgene (GSL Biotech LLC)

\section{Procedure}

A. Riboprobe synthesis

Note: DNA templates for riboprobes can be either cDNA cloned into a plasmid backbone 
Please cite this article as: Narayanan and Oates, (2019). Detection of mRNA by Whole Mount in situ Hybridization and DNA Extraction for Genotyping of

downstream of an RNA polymerase promoter or PCR product amplified from CDNA or genomic DNA. See Note 1.

1. Template preparation

\section{Preparing a template from a plasmid}

a. Linearize the plasmid by digestion with the appropriate restriction enzyme at $37^{\circ} \mathrm{C}$. Choose an enzyme such that the template is linearized immediately downstream of the cDNA insert.

Set the reaction up as:

$\begin{array}{ll}\text { Plasmid template } & 5 \mu \mathrm{g} \\ \text { Restriction enzyme } & 5 \mu \mathrm{l} \\ \text { 10x restriction buffer } & 10 \mu \mathrm{l}\end{array}$

Make up to $100 \mu \mathrm{l}$ with distilled water/nuclease-free water.

b. Purify the linearized plasmid with a commercial clean up kit. We recommend the Qiaquick PCR purification kit. Purify the plasmid as per the manufacturer's instructions and elute the plasmid in $30 \mu$ of elution buffer.

c. Dilute $1 \mu \mathrm{l}$ of the eluent in $4 \mu \mathrm{l}$ of distilled water. Use $1 \mu \mathrm{l}$ to assess concentration on a spectrophotometer and $4 \mu \mathrm{l}$ to check the linearization with agarose gel electrophoresis. A single band corresponding to the linearized plasmid should be visible on the gel. Proceed with riboprobe synthesis if a single band corresponding to the fully linearized plasmid is visualized.

\section{Preparing a template by PCR}

a. Design primers to amplify the desired target from CDNA or genomic DNA. To make a riboprobe that is complementary to the target mRNA, add the RNA polymerase (T7/T3/Sp6) promoter sequence to the reverse primer as: 5'-RNA polymerase promoter sequence + template specific sequence-3'.

\begin{tabular}{ll}
\hline RNA polymerase & Promoter sequence $\left(\mathbf{5}^{\prime} \boldsymbol{\rightarrow} \mathbf{3}^{\prime}\right)$ \\
\hline T7 & TAATACGACTCACTATAGGGAGA \\
T3 & AATTAACCCTCACTAAAGGGAGA \\
Sp6 & ATTTAGGTGACACTATAGAAGA \\
\hline
\end{tabular}

b. Carry out the PCR with the optimal cycling conditions. We recommend using a high fidelity DNA polymerase like Phusion.

c. Clean up the PCR product. We recommend the Promega SV Gel Wizard PCR purification kit. Elute in $30 \mu \mathrm{l}$ of the kit elution buffer. Dilute $1 \mu \mathrm{l}$ of the eluent in $4 \mu \mathrm{l}$ of distilled water. Use $1 \mu \mathrm{l}$ of this dilution to assess concentration on a NanoDrop and $4 \mu$ to assess product quality by gel electrophoresis. Proceed with riboprobe synthesis if a single band of the appropriate length is obtained. It is not necessary to sequence the PCR product to confirm sequence accuracy of the template (see Note 6). 
2. In vitro transcription

a. Thaw the reaction components (except the enzymes) and place on ice.

b. Set up each $20 \mu$ transcription reaction as:

DNA Template

10x Transcription buffer

rNTP-DIG

RNase Inhibitor

RNA polymerase
1-1.5 $\mu \mathrm{g}$ of linearized plasmid or 100-500 ng of PCR product

$2 \mu \mathrm{l}$

$2 \mu \mathrm{l}$

$0.5 \mu \mathrm{l}$

$2 \mu \mathrm{l}$

Adjust the volume to $20 \mu \mathrm{l}$ with RNase-free water, if needed.

c. Transcribe for $2-4 \mathrm{~h}$ at $37^{\circ} \mathrm{C}$. The yield of the reaction is equivalent when the transcription time is between $2 \mathrm{~h}$ and $4 \mathrm{~h}$.

d. Purify the riboprobe from the reaction with a commercial kit like QIAGEN RNeasy Min Elute. Follow the manufacturer's instructions and elute the riboprobe in $30 \mu \mathrm{l}$ of RNase-free water. Dilute $1 \mu \mathrm{l}$ of the probe in $4 \mu \mathrm{l}$ of water. Use $1 \mu \mathrm{l}$ to assess the concentration on a spectrophotometer and $4 \mu \mathrm{l}$ to assess the quality of the transcription by agarose gel electrophoresis. The typical $A_{280} / A_{260}$ ratio of the synthesized probe after clean up is between 1.85 and 2.00. To resolve the RNA riboprobe on a $1 \%$ agarose gel in $1 \times$ TAE, run it at $140 \mathrm{~V}$ for 10-15 min. The riboprobe should resolve as a distinct band. Occasionally, a longer band is also obtained-this is typically an electrophoresis artifact arising due to RNA secondary structure, if a high-quality PCR product or completely linearized plasmid template has been used.

e. Store the remainder of the synthesized riboprobe at $-20^{\circ} \mathrm{C}$. Dilute the riboprobe in $5 \mathrm{ml}$ of Hyb to perform in situ hybridization. See Note 2.

f. Test the probe by performing in situ hybridization and assessing the pattern of hybridization obtained.

B. In situ hybridization

Notes:

a. This protocol has been optimized for embryos up to $48 \mathrm{~h}$ post fertilization (hpf) and is carried out in 24-well plates. Use $800 \mu \mathrm{l}$ for washes and $500 \mu \mathrm{l}$ for incubations. When exchanging media, the embryos being stained should not be allowed to dry out and should always remain covered with liquid. To ensure that they do not get stuck to the bottom or on to the sides of the wells, pipette gently and check after each solution change that embryos are covered by liquid.

b. All incubation steps, unless specified, are performed at room temperature on a shaker.

1. Fixation and dehydration of embryos (see Note 3).

\section{Fixing embryos younger than $24 \mathrm{hpf}$}

a. Transfer embryos into $2 \mathrm{ml}$ microfuge tubes (for long-term storage) or into wells of a 
24-well plate (for immediate use for in situ) with a $3 \mathrm{ml}$ plastic Pasteur pipette. Up to 100 embryos can be stored in a single tube and up to 30 embryos can be processed per well in a 24-well plate.

b. Remove as much embryo medium as possible. If the embryos are in their chorions, all the liquid can be removed. Add 4\% PFA in PBST (fix)-1 ml per tube, $800 \mu \mathrm{l}$ per well. Incubate on a shaker for $5 \mathrm{~min}$ at room temperature. This step serves to remove any excess embryo medium.

c. Exchange the fix with fresh fix-up to $2 \mathrm{ml}$ per tube, $800 \mu \mathrm{l}-1 \mathrm{ml}$ per well. Incubate at room temperature for 1 to $4 \mathrm{~h}$ or overnight at $4{ }^{\circ} \mathrm{C}$, with shaking.

d. Remove the fix and add PBST-up to $2 \mathrm{ml}$ per tube, $800 \mu \mathrm{l}-1 \mathrm{ml}$ per well.

e. Transfer embryos into PBST in a $35 \mathrm{~mm}$ Petri dish with a $3 \mathrm{ml}$ plastic Pasteur pipette and use forceps to dechorionate the embryos under a stereo microscope (Video 1). Transfer embryos back into the well plate or into a fresh tube/vial. The pipette should be rinsed by pipetting up and down in PBST, and the PBST should be exchanged between batches of embryos to prevent cross-contamination.

\section{Fixing embryos older than $24 \mathrm{hpf}$}

a. From 24 hpf onwards, add PTU to the embryo medium to a final concentration of $0.003 \%$ to inhibit pigment development in the embryos.

b. Dechorionate embryos in embryo medium in a $35 \mathrm{~mm}$ Petri dish under a stereomicroscope (Video 2) and transfer them with a $3 \mathrm{ml}$ plastic Pasteur pipette to the well plate or microfuge tube vial-30 for a well, 100 for a tube. The embryo medium should be exchanged between batches of embryos to prevent cross-contamination.

c. Remove as much embryo medium as possible. Add 4\% PFA in PBST (fix)-1 ml per tube, $800 \mu \mathrm{l}$ per well. Incubate on a shaker for $5 \mathrm{~min}$ at room temperature. This step serves to remove any excess embryo medium.

d. Exchange with fresh fix-up to $2 \mathrm{ml}$ per tube or vial, $800 \mu \mathrm{l}$ to $1 \mathrm{ml}$ per well in the well plate. Incubate with shaking at room temperature for 1 to $4 \mathrm{~h}$ or overnight at $4{ }^{\circ} \mathrm{C}$.

e. Briefly rinse the embryos by removing fix and adding PBST-up to $2 \mathrm{ml}$ per tube, $800 \mu \mathrm{l}-1$ $\mathrm{ml}$ per well.

f. Exchange the PBST and wash the embryos in PBST 3 times, for a duration of 5 min each time, on a shaker at room temperature.

\section{Dehydration and permeabilization of embryos}

a. Dehydrate the embryos in a graded methanol series: add $800 \mu \mathrm{l}$ of $30 \%$ methanol in PBST, then replace with $800 \mu \mathrm{l}$ of $50 \%$ methanol in PBST and then with $800 \mu \mathrm{l}$ of $70 \%$ methanol in PBST. Incubate on a shaker between each replacement for $5 \mathrm{~min}$.

b. Incubate the embryos in $800 \mu$ of absolute methanol for 5 min on a shaker. 
c. Replace the methanol and incubate embryos at $-20{ }^{\circ} \mathrm{C}$ overnight to permeabilize the embryos. Use $1.1 \mathrm{ml}$ of methanol per well or $2 \mathrm{ml}$ per microfuge tube.

The protocol can be stopped here if necessary as embryos can be stored at $-20{ }^{\circ} \mathrm{C}$ in methanol indefinitely (see Note 3).

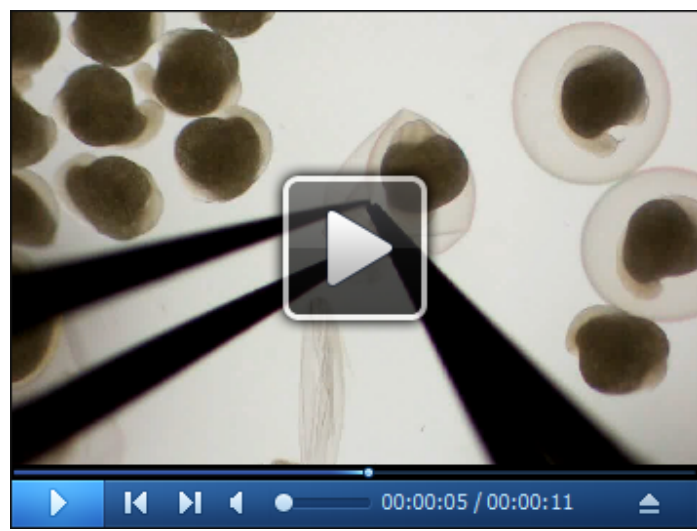

Video 1. Dechorionation of fixed somitogenesis stage embryos

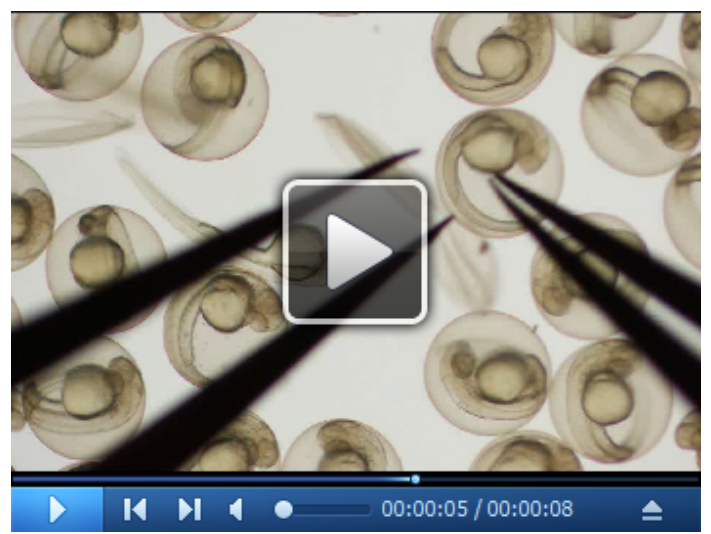

Video 2. Dechorionation of live 36 hours post fertilization (hpf) embryos

2. Enzymatic embryo permeabilization

a. Rehydrate embryos in a graded methanol series: add $800 \mu \mathrm{l}$ of $70 \%$ methanol in PBST, then replace with $800 \mu \mathrm{l}$ of $50 \%$ methanol in PBST and then with $800 \mu \mathrm{l}$ of $30 \%$ methanol in PBST. Incubate on a shaker for 5 min at each step.

b. Perform two 5-min washes with PBST.

c. Digest embryos in Proteinase K (PKA). Dilute the PKA stock 1:200 for embryos younger than $24 \mathrm{hpf}$ and 1:100 for embryos older than $24 \mathrm{hpf}$ in PBST. Incubate in $500 \mu \mathrm{l}$ without shaking at room temperature. Digestion time is embryonic stage dependent; the timings listed below can be used as a guideline. Stages indicated here are as per Kimmel et al. (1995). 
Please cite this article as: Narayanan and Oates, (2019). Detection of mRNA by Whole Mount in situ Hybridization and DNA Extraction for Genotyping of

\begin{tabular}{ll}
\hline Stage & Time for digestion \\
\hline Up to 50\% epiboly & digestion omitted \\
$50 \%$ epiboly to bud & 30 s/digestion omitted \\
$\sim 5$ somites & $2 \mathrm{~min}$ \\
$\sim 8-15$ somites & $3-4 \mathrm{~min}$ \\
$\sim 20$ somites-26 hpf & $5-7 \mathrm{~min}$ \\
$\sim 36 \mathrm{hpf}$ & $15-20 \mathrm{~min}$ \\
$\sim 48 \mathrm{hpf}$ & $20-25 \mathrm{~min}$ \\
\hline
\end{tabular}

d. Stop the reaction by making a rapid exchange with PBST followed by a 20-min re-fixation with $500 \mu \mathrm{l}$ of fix at room temperature on a shaker.

e. Remove the fix; perform one rapid wash with PBST followed by two 5-min PBST washes.

3. Hybridization

Note: The temperature used for hybridization is probe-dependent, but a good starting temperature is $60{ }^{\circ} \mathrm{C}$ (see Note 4). Perform hybridization steps in a water bath set to the hybridization temperature. Use a thin-walled plastic container lined with moistened tissue to incubate the well plate in the water bath. The container and hybridization solutions need to be pre-warmed to the hybridization temperature in the water bath before use.

a. Pre-hybridize in $500 \mu \mathrm{l}$ of $\mathrm{Hyb}$ at the hybridization temperature for a minimum of $30 \mathrm{~min}$. Embryos can be pre-hybridized for up to $3 \mathrm{~h}$ at the hybridization temperature.

b. Remove the Hyb and replace it with $500 \mu$ l of labeled riboprobe diluted in Hyb. Hybridize overnight at the hybridization temperature. See Note 5.

4. Post-hybridization washes

Note: These washes are also performed in a water bath at the hybridization temperature. Prepare the wash solutions fresh and warm them in the water bath before use. Timings indicated in this step are critical-do not wash for shorter or longer than the time recommended.

a. Remove and recycle probe. Store it at $-20^{\circ} \mathrm{C}$. See Note 2 .

b. Wash embryos 2 times, for 30 min each time in Wash 1.

c. Wash embryos for 15 min in Wash 2.

d. Wash embryos 2 times, for 30 min each time in Wash 3.

5. Detection

a. Make a quick rinse with MABT to remove any remaining Wash 3 from the embryos.

b. Add $500 \mu \mathrm{l}$ of $2 \%$ blocking reagent and incubate without shaking in the dark at room temperature for at least $30 \mathrm{~min}$.

c. Dilute AP-conjugated anti-DIG antibody $1: 2,000$ in $2 \%$ blocking reagent. Remove the blocking reagent and add $500 \mu \mathrm{l}$ of the diluted antibody in blocking reagent to the embryos. Incubate for $2 \mathrm{~h}$, without shaking, at room temperature in the dark.

d. Remove antibody solution and make 2 quick washes with MABT.

e. Wash in 10-20 min intervals over 1 to $2 \mathrm{~h}$ at room temperature; at least 6 exchanges of 
MABT should be made. Alternatively, embryos can be washed at $4{ }^{\circ} \mathrm{C}$ overnight in MABT, followed by three 5 -min washes the next day.

f. Equilibrate embryos in freshly prepared staining buffer twice for 5 min each.

g. Add $500 \mu \mathrm{l}$ of the staining solution to the embryos. Stain in the dark at room temperature without shaking. See Note 5.

h. Control the staining reaction by eye under a stereomicroscope. Place the well plate on a white background and illuminate the plate from above. Monitor the development of the embryos in the first 5 min after the staining solution has been added and then in 10-15 min intervals till the stain saturates or the desired contrast is achieved.

i. Stop the staining reaction by performing three 5-min washes in PBST.

j. Incubate embryos in methanol at room temperature till the yolk is cleared and appears white, or overnight at $4{ }^{\circ} \mathrm{C}$ or $-20^{\circ} \mathrm{C}$.

Note: See Figures 2, 3B and 4B for stains we have made with this protocol. See Note 6 for notes on troubleshooting.

6. Mounting and photography

a. Remove the methanol from the embryos by making two 5-min washes in PBST.

b. Re-fix in 4\% PFA in PBST for at least 15 min at room temperature.

c. Wash embryos twice each for 5 min in PBST.

d. Add $87 \%$ glycerol to the embryos and leave to equilibrate at $4{ }^{\circ} \mathrm{C}$. When the embryos sink to the bottom of the well, they are completely equilibrated. This takes $\sim 12 \mathrm{~h}$. Embryos can be subsequently stored in $87 \%$ glycerol either at $4{ }^{\circ} \mathrm{C}$ or $-20^{\circ} \mathrm{C}$.

e. Photograph the embryos:

i. Photographing whole mount preparations:

Photograph the embryos in $87 \%$ glycerol in a $35 \mathrm{~mm}$ Petri dish or an imaging mold (see Note 7) with an RGB camera coupled to a stereomicroscope. Illuminate the embryos from above using a ring light. Place a white sheet of paper below the dish to provide a white background for the image. An eyelash, tungsten wire or fine pipette tip can be used to manipulate the embryos.

ii. Photographing flat mount preparations:

See also the JoVE video protocol for de-yolking and flat mounting (Cheng et al., 2014).

1) Transfer the embryos to be flat mounted onto a glass slide with a drop of $87 \%$ glycerol. De-yolk the embryos with an eyelash or sharpened tungsten wire (see Note 8 ) in the drop. Move the embryo to the edge of the drop so that a minimal volume of glycerol covers it. Remove the remaining yolk cells with the eyelash. Periodically rinse the loosened yolk cells off the embryo in the glycerol drop. Move the embryo to a fresh drop of glycerol after de-yolking.

2) Place the embryonic axis, dorsal side up, on a clean glass slide with the wire or the eyelash. Place approximately $15-20 \mu$ total volume of $87 \%$ glycerol in small drops 
next to the embryos. Up to 10 de-yolked embryos can be flat mounted on a single slide.

3) Make 4 small grease pillars with a $10 \mu$ pipette tip to hold the corners of a glass coverslip in place. Carefully lower the coverslip onto the slide (Figure 1).

4) Seal the 4 edges of the coverslip with transparent nail varnish.

5) Photograph the embryos with transmitted light on a stereoscope with an RGB camera.
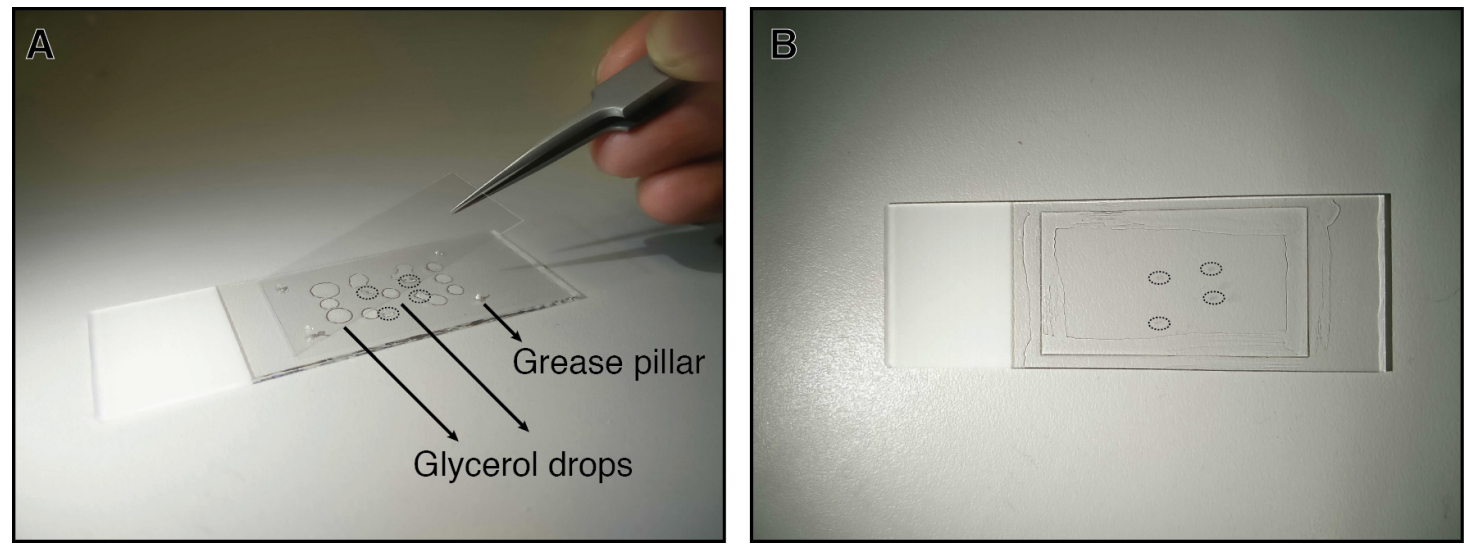

Figure 1. Preparing a flat mount. A. Placing drops of glycerol next to de-yolked embryos (circled) and gently lowering a coverslip on the slide that will be held in place by grease pillars at the corners. B. The finished slide with flat mounted embryos (circled) and coverslip edges sealed with transparent nail varnish.

\section{Genotyping}

Note: Genomic DNA can be extracted from intact embryos or from tissue fragments after in situ hybridization. Fragments of tissue are taken before de-yolking and flat mounting the embryos. Perform the following steps in PCR tubes-1 embryo per tube.

1. Select the embryos to be genotyped and rinse them together in a small Petri dish or singly in PCR tubes with PBST to remove the glycerol. A few rapid exchanges followed by three 5-min washes on a shaker at room temperature are typically sufficient.

2. Transfer the whole embryo with forceps into a PCR tube. If DNA is being extracted from tissue fragments, transfer the embryo onto a glass slide into a 15-20 $\mu$ drop of PBST. Cut one-third to one-half of the embryo that is not stained with a micro knife. Transfer the piece to a PCR tube. Ensure that no excess liquid is transferred. Add $87 \%$ glycerol to the tissue on the glass slide to continue with de-yolking and flat mounting.

3. Add $15 \mu \mathrm{l}$ of $1 \mathrm{x}$ base solution to the tube and incubate at $95^{\circ} \mathrm{C}$ for $30 \mathrm{~min}$.

4. Bring to room temperature and add $15 \mu \mathrm{l}$ of $1 \mathrm{x}$ neutralization solution.

Note: This solution is PCR ready (see Note 9). 


\section{Data analysis}

1. Whole mount mRNA in situ hybridization coupled to chromogenic detection is a qualitative assay for gene expression in the embryo. In the whole mount format, the distribution of the mRNA of interest in specific tissue(s) at a developmental stage of interest can be assessed. Performing mRNA in situ hybridization for a target in embryos fixed at different developmental stages can help the investigator characterize temporal changes in the mRNA expression of the gene of interest over the course of development.

In situ hybridization can also be utilized to assess the effect of the loss or knock down of gene function on the expression of genes of interest. For example, in situ hybridization has been used in our laboratory to assay the wave patterns of cyclic genes arising from their transcriptional oscillations in zebrafish embryos during somitogenesis and to demonstrate that loss of function mutant cyclic gene alleles lead to the loss of these wave patterns (Figure 1, Lleras Forero et al., 2018). Working from a set of microscope images of embryos, in situ hybridization can also be used as a semi-quantitative endpoint assay to measure the spatio-temporal effects of an experimental perturbation, for example to investigate the upregulation or downregulation of Wnt signaling (Figures 3, 5 and 6, Bajard et al., 2014). mRNA in situ hybridization has also been used to perform a comparison between the spatial distribution of endogenous cyclic gene expression and a transgenic reporter (Figure S1, Soroldoni et al., 2014). However, care must be taken in interpreting results that depend on the intensity of the chromogenic signal, either qualitatively, or after quantifying the intensity of the signal with a tool such as plot profile in Fiji (https://fiji.sc/), as the intensity of the stain is initially development time-dependent, but the enzymatic reaction can later saturate.

2. Designing a genotyping strategy from the extracted genomic DNA will depend entirely on the nature of the specific alleles in the experiment. For some alleles, base transitions will lead to the gain or loss of a site for restriction digestion, allowing for a restriction digestion-based analysis of the PCR amplicon obtained from the genomic DNA using primers specific for the gene of interest. When such a strategy is not possible, the PCR amplicon can be sequenced. Analysis of genotyping sequence data generated can be done with open source or commercially available software (Snapgene, GSL Biotech LLC). For example, we detected base-pair transitions causative for a TALEN induced her1 mutation in a her7 $7^{\text {hu2124 }}$ background initially by sequencing (Figure S1, Lleras Forero et al., 2018). The mutation led to the loss of a restriction site and embryos were subsequently genotyped by the resistance of the her1 mutant allele to restriction digestion.

\section{Notes}

1. Riboprobe design

In general, using long probes provides a good stain. Long probes yield hybrids with high 
thermal stability and provide greater signal amplification. Therefore, a good general approach is to design a riboprobe that is complementary to the entire coding sequence of the mRNA. However, such an approach might not be suitable in all cases. For example, to distinguish between mRNAs of paralogs, designing a shorter riboprobe with high complementarity to the paralog of interest is the better approach. In our hands, probes of approximately 300-3,200 bp lengths have reliably yielded a good stain with this protocol (Figure 2).

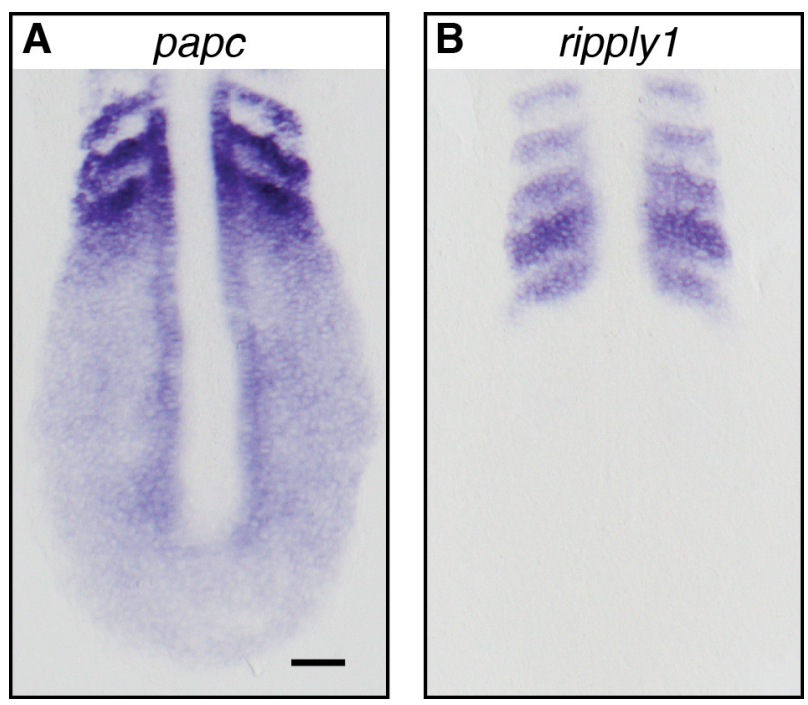

Figure 2. Representative results of the in situ hybridization protocol using riboprobes of lengths $\sim \mathbf{3 0 0}$ and $\mathbf{3 , 2 0 0}$ base pairs. A. Stain for paraxial protocadherin (papc/pcdh8) using a riboprobe of 3,137 base pair length, antisense to the coding region of papc mRNA (Yamamoto et al., 1998). B. Stain for ripply1 using a 325 base pair riboprobe, antisense to the coding region of ripply1 mRNA (Lleras et al., 2018). Hybridization has been performed at $60^{\circ} \mathrm{C}$ on 10 -somite stage wild-type embryos. Flat mounted preparations are shown here oriented with the posterior towards the bottom of the panels. Scale bar is $50 \mu \mathrm{m}$ and applies to both panels.

\section{Probe concentration}

The final working concentration of the probe should be optimized experimentally. In general, concentrations of 0.3-1 $\mathrm{ng} / \mathrm{\mu l}$ produce a good in situ stain; however, working concentrations should be titrated every time a new probe is synthesized. The probe can be recycled and reused many times. Note down the initial volume, as the probe will dilute over time and fail to produce a high contrast stain.

3. Embryo fixation and storage

Embryos can be fixed and dehydrated ahead of time. The quality of the fix will affect the signal to noise ratio of the stain. Freshly prepared fix gives the best results, but fix up to a week old can be used. Embryos should not be incubated in fix for more than $4 \mathrm{~h}$ at room temperature or 1 week at $4{ }^{\circ} \mathrm{C}$. Fixed and dehydrated embryos can be stored in methanol at $-20^{\circ} \mathrm{C}$ indefinitely.

4. Hybridization temperature 
The hybridization temperature is probe-dependent and has to be experimentally determined for each probe. The choice of temperature also sets the stringency of the protocol-stringency can be increased by increasing the hybridization temperature and decreased by lowering it. When using probes that need to discriminate between targets with high sequence similarity, the stringency of the protocol needs to be raised to favor the formation of the desired RNA hybrids as a $1 \%$ base pair mismatch decreases the thermal stability of RNA-RNA duplexes by roughly $1{ }^{\circ} \mathrm{C}$ (Wetmur et al., 1976).

In our hands, a good starting temperature has been $60{ }^{\circ} \mathrm{C}$ for probes designed to detect the coding sequence of the target mRNA (Figures 2 and 3). For short probes and intronic probes, $55^{\circ} \mathrm{C}$ has been used as the starting temperature. The hybridization temperature has then been optimized by changing the temperature in $2^{\circ} \mathrm{C}$ steps.
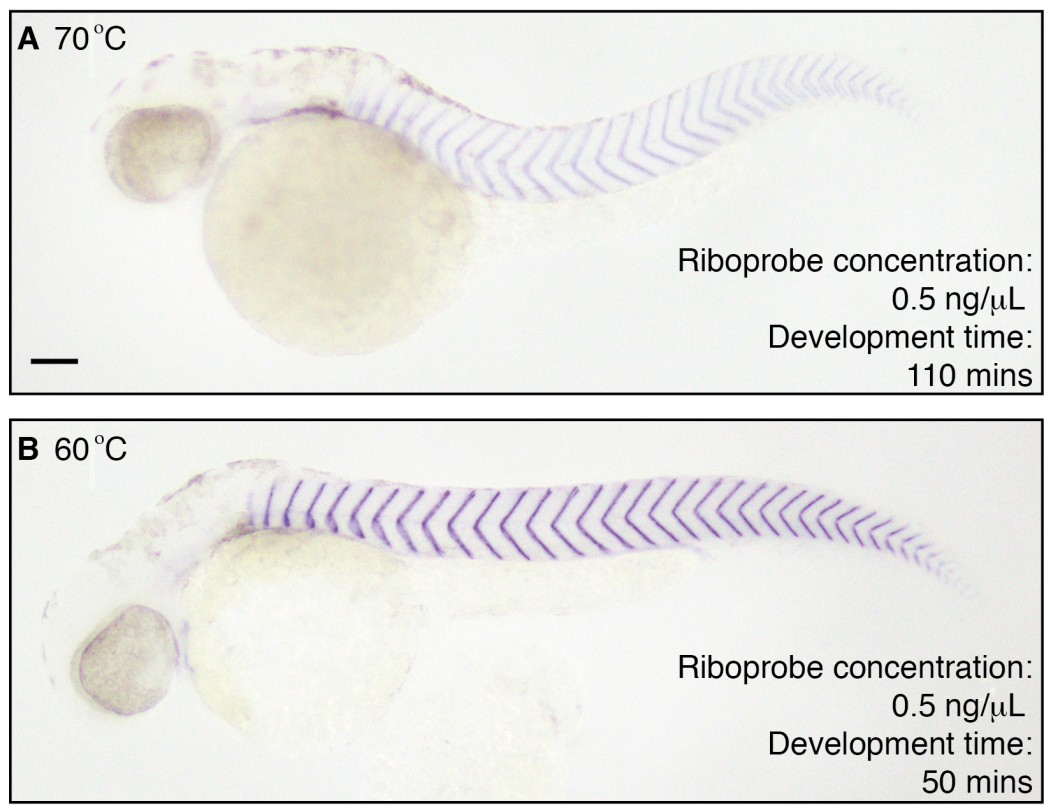

Figure 3. Hybridization at $60{ }^{\circ} \mathrm{C}$ is sufficiently stringent to achieve a high contrast final stain with a specific probe. In situ hybridization to detect xirp2a (Deniziak et al., 2007) performed at $70{ }^{\circ} \mathrm{C}$ and $60{ }^{\circ} \mathrm{C}$ in $36 \mathrm{hpf}$ wild-type embryos. A. Stain after $110 \mathrm{~min}$ of development when probe is hybridized at $70{ }^{\circ} \mathrm{C}$. B. Stain after 50 min of development when hybridized at $60^{\circ} \mathrm{C}$. Riboprobe concentration used is $0.5 \mathrm{ng} / \mu \mathrm{l}$ in hybridization buffer. Scale bar is $100 \mu \mathrm{m}$ and applies to both panels.

5. Improving contrast of the stain

Adding dextran sulfate to the hybridization buffer will yield high contrast stains with a relatively short development time, compared to stains produced without dextran sulfate (Figure 4). If long development times are required to detect the target mRNA, adding 10\% PVA to the staining solution will decrease the rate at which background staining will develop. 


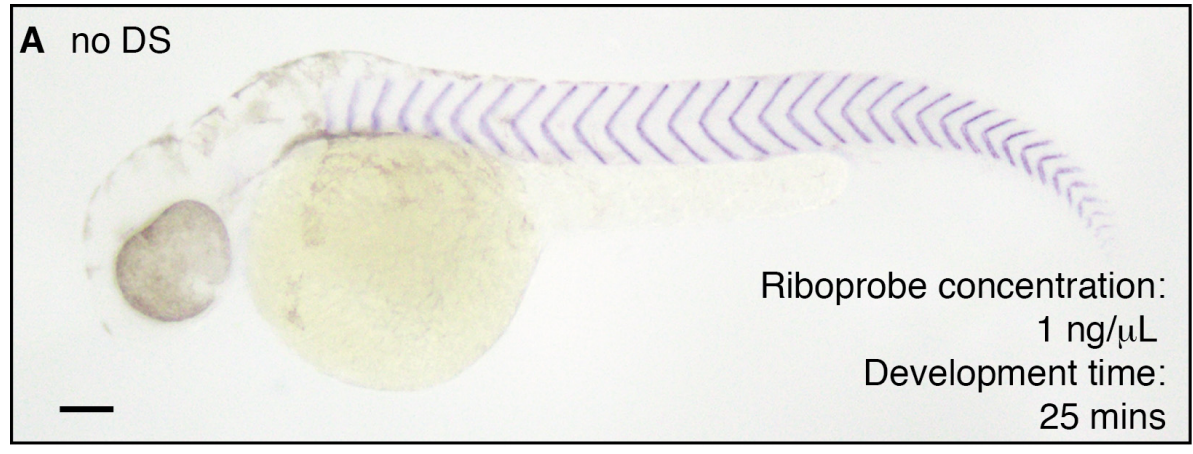

B $5 \%$ DS

Riboprobe concentration:

$1 \mathrm{ng} / \mu \mathrm{L}$

Development time:

25 mins

Figure 4. Addition of dextran sulfate to the hybridization buffer enhances the contrast of the final stain. In situ hybridization to detect xirp2a performed at $60^{\circ} \mathrm{C}$ in $36 \mathrm{hpf}$ wild-type embryos. A. Stain after 25 min of development when probe is hybridized in hybridization buffer B. Stain after 25 mins of development when probe is hybridized in hybridization buffer with $5 \%$ dextran sulfate (DS). Riboprobe concentration used is $1 \mathrm{ng} / \mu \mathrm{l}$. Scale bar is $100 \mu \mathrm{m}$ and applies to both panels.

6. Troubleshooting

\section{No signal from an antisense riboprobe}

In vitro transcription has not been successful: The integrity of the plasmid could have been compromised. Re-prep the plasmid or generate a template by PCR.

\section{Sub-optimal signal to noise ratio}

a. Poor quality probe: Control for probe quality by performing agarose gel electrophoresis of templates and synthesized riboprobes. They should resolve as distinct bands. Templates can be sequenced to assess sequence accuracy.

b. Probe concentration is too high: Diluting the probe can reduce the background.

c. Background due to non-specific hybridization: Increase the stringency of the protocol by raising the hybridization temperature.

d. Background due to prolonged development: Reduce the hybridization temperature to lower the stringency of the protocol, add 10\% PVA to the staining solution.

\section{Poor signal intensity}

a. Probe is too dilute: Synthesize new probe, increase the concentration of the probe. 
b. Probe design: Increase the length of the probe for better signal amplification.

c. Hybridization is too stringent: Decrease the hybridization temperature.

d. Add $5 \%$ dextran sulfate to the hybridization buffer.

7. Mold for photography of whole mount preparations

An imaging dish for photographing whole mount specimens can be made by casting a mold for the embryos in $1-1.5 \%$ agarose in distilled water using a polydimethylsiloxane (PDMS) negative. This negative is cast from a positive made from Perspex plastic machined with the conical depressions of the desired diameter and depth (Figure 4B, the positive and negative for the imaging mold are made by our laboratory and are described in Herrgen et al., 2009). Add $87 \%$ glycerol to the dish. Transfer the stained embryos into the mold and orient them using the tip of a tungsten wire, an eyelash or a fine pipette tip such that their yolks fit in the conical depressions under a stereomicroscope (Figure 5).

A
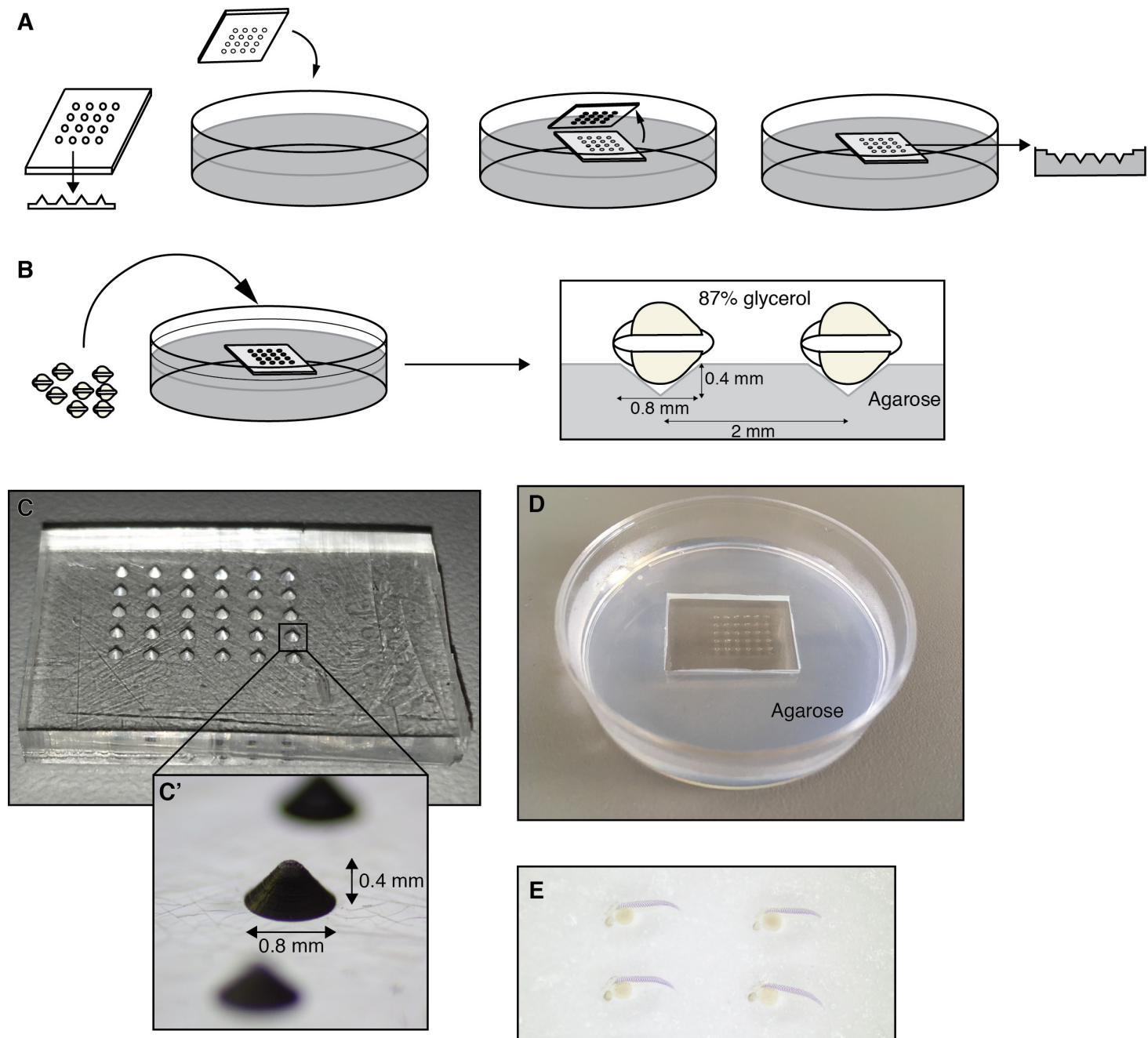

E

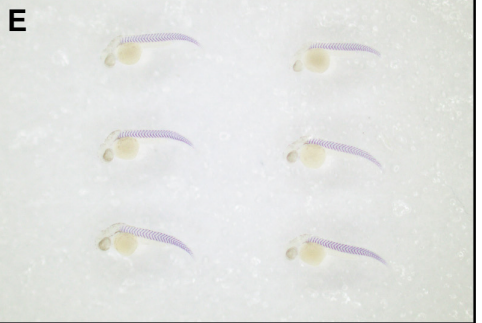

Figure 5. Preparing to document the whole mount in situ hybridization preparations. A PDMS negative with an array of raised cones of $0.8 \mathrm{~mm}$ diameter and $0.4 \mathrm{~mm}$ height is used to 
cast the agarose mold with conical depressions. The yolk of the embryos fits into the depressions and embryos can be oriented laterally such that they lie flat on the surface of the agarose. A. Casting a mold to orient embryos in 1\%-1.5\% agarose. B. Embryos are oriented in the conical cavities of the mold in $87 \%$ glycerol. C-C'. Polydimethylsiloxane (PDMS) negative used to cast the mold. D. Agarose mold for the embryos. E. Embryos oriented for photography.

8. De-yolking the embryo

a. We recommend referring to the video protocol for de-yolking and flat mounting (Cheng et al., 2014).

b. A sharpened tungsten wire or "hook" can be used instead of an eyelash for de-yolking embryos. To sharpen and shape the wire, fire-polish the end of the tungsten wire by holding the last 0.5 to $1 \mathrm{~cm}$ length of the wire in a Bunsen burner flame until it glows orange for $30-60 \mathrm{~s}$. With a pair of forceps shape the flamed wire into a hook in $87 \%$ glycerol. Detailed instructions to make the tungsten hook and holder are provided in Picker et al., 2009.

9. Using the embryo extract for PCR

A dilution series ranging from no dilution up to $1: 5$ in distilled water should be trialed to find the optimal volume of genomic DNA extract that is necessary for PCR for a given embryonic stage. Extracts from 8 to 10-somite stage whole embryos and embryo fragments typically do not need any further dilution and 1-2 $\mu \mathrm{l}$ can be used per $10 \mu \mathrm{l} \mathrm{PCR}$ reaction. Extracts from tissue of 24-36 hpf embryos typically need to be diluted 1:4.

\section{$\underline{\text { Recipes }}$}

Note: This protocol does not require DEPC treated water or solutions or specific RNase free conditions. Distilled or ultrapure water, autoclaved glassware and single use polypropylene consumables such as microfuge tubes, centrifuge tubes, plastic Pasteur pipettes micropipette tips are sufficient.

1. $1 \times \mathrm{TAE}$

$40 \mathrm{mM}$ Tris-acetate

$20 \mathrm{mM}$ Acetate

1 mM EDTA

$\mathrm{pH} 8.3$

Dilute 10X TAE 1:10 in ultrapure water

Store at room temperature

To make $1 \mathrm{~L}$ of 10X TAE (0.4 M Tris-acetate, $0.2 \mathrm{M}$ Acetate and $0.1 \mathrm{M}$ EDTA):

$48.5 \mathrm{~g}$ Tris base

$11.4 \mathrm{ml}$ glacial acetic acid

$20 \mathrm{ml} 0.5 \mathrm{M}$ EDTA, pH 8.0 
Make up to $1 \mathrm{~L}$ with ultrapure water

Autoclave

2. $100 \times$ PTU stock (0.3\% [weight by volume] in distilled water) $(100 \mathrm{ml})$

Dissolve $0.3 \mathrm{~g} \mathrm{~N}$-Phenylthiourea (PTU) in $100 \mathrm{ml}$ of distilled water with heating and stirring (store in the dark at room temperature)

3. $10 \%$ Tween-20 (dilute Tween-20 1:10 in distilled water) $(100 \mathrm{ml})$

$10 \mathrm{ml}$ Tween-20

Make up to $100 \mathrm{ml}$ with distilled water

Stir till a homogeneous solution is achieved

Store at room temperature

4. PBST

$137 \mathrm{mM} \mathrm{NaCl}$

$2.7 \mathrm{mM} \mathrm{KCl}$

$10 \mathrm{mM} \mathrm{Na}_{2} \mathrm{HPO}_{4}$

$1.8 \mathrm{mM} \mathrm{KH}_{2} \mathrm{PO}_{4}$ in distilled water, $\mathrm{pH} 7.4$

$0.1 \%$ Tween-20

\section{To make 1 L PBST:}

$8 \mathrm{~g} \mathrm{NaCl}$

$0.2 \mathrm{~g} \mathrm{KCl}$

$1.44 \mathrm{~g} \mathrm{Na}_{2} \mathrm{HPO}_{4}$

$0.24 \mathrm{~g} \mathrm{KH}_{2} \mathrm{PO}_{4}$

Make up to $1 \mathrm{~L}$ with distilled water after adjusting $\mathrm{pH}$ and autoclave

Add $10 \mathrm{ml}$ of $10 \%$ Tween-20

Store at room temperature

5. $4 \%$ PFA in PBST (4\% weight by volume in PBST) $(100 \mathrm{ml})$

a. Pre-warm $100 \mathrm{ml}$ PBS to $68^{\circ} \mathrm{C}$ in a water bath

\section{Add $4 \mathrm{~g}$ PFA}

Incubate at $68{ }^{\circ} \mathrm{C}$ with periodic agitation for $50-60$ mins

Add $1 \mathrm{ml}$ of $10 \%$ Tween-20 when the solution has cooled to room temperature

Store for up to a week at $4{ }^{\circ} \mathrm{C}$

Note: The PFA should dissolve in 50 min to $1 \mathrm{~h}$

OR

b. Dilute $16 \%$ PFA 1:4 in PBST. Store for up to a week at $4{ }^{\circ} \mathrm{C}$

6. Proteinase $\mathrm{K}$ stock

$1 \mathrm{mg} / \mathrm{ml}$ in distilled water

Store as aliquots at $-20^{\circ} \mathrm{C}$

7. $20 \times \mathrm{SSC}$

$3 \mathrm{M} \mathrm{NaCl}$

$300 \mathrm{mM}$ tri-sodium citrate 
$\mathrm{pH} 7.0-7.2$

To make 1 L 20x SSC:

$175.2 \mathrm{~g} \mathrm{NaCl}$

$88.2 \mathrm{~g}$ tri-sodium citrate

Make up to $1 \mathrm{~L}$ with distilled water after adjusting $\mathrm{pH}$

Autoclave

Store at room temperature

8. $50 \mathrm{mg} / \mathrm{ml}$ Heparin stock

Dissolve in Heparin in distilled water to a final concentration of $50 \mathrm{mg} / \mathrm{ml}$

Store at $4{ }^{\circ} \mathrm{C}$

9. Hybridization buffer ( $\mathrm{Hyb})$

$50 \%$ Formamide

$5 \times \mathrm{SSC}$

$50 \mu \mathrm{g} / \mathrm{ml}$ Heparin

$0.5 \mathrm{mg} / \mathrm{ml}$ Torula-RNA

$0.1 \%$ Tween-20

Optional: $5 \%$ weight by volume dextran sulfate

To make $\mathbf{5 0} \mathrm{ml} \mathrm{Hyb:}$

$25 \mathrm{ml}$ formamide

$12.5 \mathrm{ml} 20 \times \mathrm{SSC}$

$50 \mu$ Heparin stock

$25 \mathrm{mg}$ Torula-RNA

$2.5 \mathrm{~g}$ dextran sulfate

Vortex well till a homogenous is achieved

Add $500 \mu \mathrm{l} 10 \%$ Tween-20

Make up to $50 \mathrm{ml}$ with distilled water

Store at $-20^{\circ} \mathrm{C}$

Note: Dextran sulfate is omitted from hyb used for pre-hybridization.

10. Post hybridization washes

Wash 1: 50\% Formamide, 2x SSC, 0.1\% Tween-20 in distilled water

To make $50 \mathrm{ml}$ :

$25 \mathrm{ml}$ Formamide

$5 \mathrm{ml} 20 \times$ SSC

$500 \mu \mathrm{l} \mathrm{10 \%} \mathrm{Tween-20}$

Make up to $50 \mathrm{ml}$ with distilled water

Wash 2: 2x SSC, $0.1 \%$ Tween-20 in distilled water

To make $50 \mathrm{ml}$ :

$5 \mathrm{ml} 20 \times \mathrm{SSC}$

500 l 10\% Tween-20 
Make up to $50 \mathrm{ml}$ with distilled water

Wash 3: $0.2 x$ SSC, $0.1 \%$ Tween-20 in distilled water

To make $50 \mathrm{ml}$ :

$500 \mu \mathrm{l} 20 x$ SSC

$500 \mu \mathrm{l} \mathrm{10 \%}$ Tween-20

Make up to $50 \mathrm{ml}$ with distilled water

Note: Make the appropriate volume of wash solution fresh.

11. MABT

100 mM Maleic Acid

$150 \mathrm{mM} \mathrm{NaCl}$ in distilled water

$\mathrm{pH} 7.5$

$0.1 \%$ Tween-20

To make $1 \mathrm{~L}$ :

$8.77 \mathrm{~g}$ maleic acid

$11.6 \mathrm{~g} \mathrm{NaCl}$

Adjust $\mathrm{pH}$ with $\mathrm{NaOH}$ pellets

Make up to $1 \mathrm{~L}$ with distilled water

Autoclave

Add $10 \mathrm{ml}$ 10\% Tween-20

Store at room temperature

12. $10 \%$ blocking reagent (Roche block)

Prepare $10 \%$ blocking reagent in MAB as per the manufacturer's instructions

Store at $-20^{\circ} \mathrm{C}$ as aliquots

13. $2 \%$ Blocking reagent in MABT (2\% Roche block)

Dilute 10\% blocking reagent (Roche block) 1:5 in MABT

Make fresh

14. Staining buffer

$100 \mathrm{mM}$ Tris- $\mathrm{HCl}, \mathrm{pH} 9.5$

$100 \mathrm{mM} \mathrm{NaCl}$

$50 \mathrm{mM} \mathrm{MgCl}_{2}$ in distilled water

To make $50 \mathrm{ml}$ :

$5 \mathrm{ml} 1 \mathrm{M}$ Tris- $\mathrm{HCl}, \mathrm{pH} 9.5$

$5 \mathrm{ml} 1 \mathrm{M} \mathrm{NaCl}$

$2.5 \mathrm{ml} 1 \mathrm{M} \mathrm{MgCl}_{2}$

$500 \mu \mathrm{l} \mathrm{10 \%} \mathrm{Tween-20}$

Note: Make fresh.

15. Staining solution

$4.5 \mu \mathrm{l}$ of NBT and $3.5 \mu \mathrm{l}$ of BCIP per $1 \mathrm{ml}$ of the staining buffer

Vortex to mix 


\section{Protect from light}

Note: Prepare the appropriate volume fresh.

Optional: add PVA to a final concentration of $10 \%$, weight by volume

\section{To make $10 \mathrm{ml}$ of staining solution with $10 \%$ PVA:}

Add $1 \mathrm{~g}$ PVA to $10 \mathrm{ml}$ of staining buffer (without Tween-20)

Bring into solution with stirring and heating

Cool to room temperature

Add $45 \mu \mathrm{l} \mathrm{NBT}$ and $35 \mu \mathrm{l}$ of BCIP

Vortex to mix

Protect from light

Note: $10 \mathrm{ml}$ is the minimum volume that can be made.

16. $87 \%$ glycerol in distilled water (weight by weight)

\section{To make $100 \mathrm{~g}$ :}

$87 \mathrm{~g}$ glycerol in $13 \mathrm{~g}$ distilled water

Stir till a homogenous solution is achieved

Store at room temperature

17. $50 x$ base solution

\section{$1.25 \mathrm{M} \mathrm{KOH}$ \\ $10 \mathrm{mM}$ EDTA in distilled water}

\section{To make $200 \mathrm{ml}$ :}

$14 \mathrm{~g} \mathrm{KOH}$

$4 \mathrm{ml} 0.5 \mathrm{M}$ EDTA

Add distilled water to a final volume of $200 \mathrm{ml}$

Store at room temperature

18. $1 x$ base solution

Dilute 50x base solution 1:50 in distilled water

Note: Prepare the appropriate volume fresh.

19. $50 x$ neutralization solution

$2 \mathrm{M}$ Tris- $\mathrm{HCl}$ in distilled water

To make $200 \mathrm{ml}$ :

$63 \mathrm{~g}$ Tris- $\mathrm{HCl}$

Add distilled water to a final volume of $200 \mathrm{ml}$

Store at room temperature

20. $1 \times$ neutralization solution

Dilute 50x neutralization solution 1:50 in distilled water

Note: Prepare the appropriate volume fresh. 
Please cite this article as: Narayanan and Oates, (2019). Detection of mRNA by Whole Mount in situ Hybridization and DNA Extraction for Genotyping of Zebrafish Embryos, Bio-protocol 9 (6): e3193. DOI: 10.21769/BioProtoc.3193.

\section{Acknowledgments}

The protocol presented here is based on G. Hauptmann's work (PMID: 11252185), which was implemented and continuously improved by D. Soroldoni. We acknowledge A. Faro and G. Gestri of the Wilson laboratory at UCL, UK who shared the genomic DNA extraction protocol with us. We also thank $O$. Venzin of the Oates lab for constructive feedback on the manuscript.

Funding: Institutional support from the Swiss Federal Institute of Technology in Lausanne (EPFL) (to ACO and RN); The Francis Crick Institute (receiving its core funding from Cancer Research UK, the Medical Research Council, and Wellcome) (to ACO and RN); Wellcome (WT098025MA to ACO); the Medical Research Council (MC_UP_1202/3 to ACO and RN).

\section{Competing interests}

The authors declare no competing interests.

\section{References}

1. Bajard, L., Morelli, L. G., Ares, S., Pecreaux, J., Julicher, F. and Oates, A. C. (2014). Wnt-regulated dynamics of positional information in zebrafish somitogenesis. Development 141(6): 1381-1391.

2. Cheng, C. N., Li, Y., Marra, A. N., Verdun, V. and Wingert, R. A. (2014). Flat mount preparation for observation and analysis of zebrafish embryo specimens stained by whole mount in situ hybridization. J Vis Exp(89). doi: 10.3791/51604.

3. Choi, H. M., Chang, J. Y., Trinh le, A., Padilla, J. E., Fraser, S. E. and Pierce, N. A. (2010). Programmable in situ amplification for multiplexed imaging of mRNA expression. Nat Biotechnol 28(11): 1208-1212.

4. Deniziak, M., Thisse, C., Rederstorff, M., Hindelang, C., Thisse, B. and Lescure, A. (2007). Loss of selenoprotein $\mathrm{N}$ function causes disruption of muscle architecture in the zebrafish embryo. Exp Cell Res 313(1): 156-167.

5. Gross-Thebing, T., Paksa, A. and Raz, E. (2014). Simultaneous high-resolution detection of multiple transcripts combined with localization of proteins in whole-mount embryos. BMC Biol 12: 55.

6. Hauptmann, G. and Gerster, T. (1994). Two-color whole-mount in situ hybridization to vertebrate and Drosophila embryos. Trends Genet 10(8): 266.

7. Herrgen, L., Schroter, C., Bajard, L. and Oates, A. C. (2009). Multiple embryo time-lapse imaging of zebrafish development. Methods Mol Biol 546: 243-254.

8. Jambor, H., Surendranath, V., Kalinka, A. T., Mejstrik, P., Saalfeld, S. and Tomancak, P. (2015). Systematic imaging reveals features and changing localization of mRNAs in Drosophila development. Elife 4: e05003. 
Please cite this article as: Narayanan and Oates, (2019). Detection of mRNA by Whole Mount in situ Hybridization and DNA Extraction for Genotyping of

9. Kimmel, C. B., Ballard, W. W., Kimmel, S. R., Ullmann, B. and Schilling, T. F. (1995). Stages of embryonic development of the zebrafish. Dev Dyn 203(3): 253-310.

10. Kiyama, H. and Emson, P. C. (1991). An in situ hybridization histochemistry method for the use of alkaline phosphatase-labeled oligonucleotide probes in small intestine. $\mathrm{J}$ Histochem Cytochem 39(10): 1377-1384.

11. Lauter, G., Soll, I. and Hauptmann, G. (2011). Two-color fluorescent in situ hybridization in the embryonic zebrafish brain using differential detection systems. BMC Dev Biol 11: 43.

12. Little, S. C., Tikhonov, M. and Gregor, T. (2013). Precise developmental gene expression arises from globally stochastic transcriptional activity. Cell 154(4): 789-800.

13. Lleras Forero, L., Narayanan, R., Huitema, L. F., VanBergen, M., Apschner, A., Peterson-Maduro, J., Logister, I., Valentin, G., Morelli, L. G., Oates, A. C. and Schulte-Merker, S. (2018). Segmentation of the zebrafish axial skeleton relies on notochord sheath cells and not on the segmentation clock. Elife 7: e33843.

14. McConaughy, B. L., Laird, C. D. and McCarthy, B. J. (1969). Nucleic acid reassociation in formamide. Biochemistry 8(8): 3289-3295.

15. Picker, A., Roellig, D., Pourquié, O., Oates, A. C. and Brand, M. (2009). Tissue micromanipulation in zebrafish embryos. Methods Mol Biol 546: 153-172.

16. Schindelin, J., Arganda-Carreras, I., Frise, E., Kaynig, V., Longair, M., Pietzsch, T., Preibisch, S., Rueden, C., Saalfeld, S., Schmid, B., Tinevez, J. Y., White, D. J., Hartenstein, V., Eliceiri, K., Tomancak, P. and Cardona, A. (2012). Fiji: an open-source platform for biological-image analysis. Nat Methods 9(7): 676-682.

17. Schulte-Merker, S., Ho, R. K., Herrmann, B. G. and Nusslein-Volhard, C. (1992). The protein product of the zebrafish homologue of the mouse $T$ gene is expressed in nuclei of the germ ring and the notochord of the early embryo. Development 116(4): 1021-1032.

18. Schulte-Merker, S., van Eeden, F. J., Halpern, M. E., Kimmel, C. B. and Nüsslein-Volhard, C. (1994). No tail (nt) is the zebrafish homologue of the mouse T (Brachyury) gene. Development 120(4): 1009-1015.

19. Soroldoni, D., Jorg, D. J., Morelli, L. G., Richmond, D. L., Schindelin, J., Julicher, F. and Oates, A. C. (2014). Genetic oscillations. A Doppler effect in embryonic pattern formation. Science 345(6193): 222-225.

20. Stapel, L. C., Lombardot, B., Broaddus, C., Kainmueller, D., Jug, F., Myers, E. W. and Vastenhouw, N. L. (2016). Automated detection and quantification of single RNAs at cellular resolution in zebrafish embryos. Development 143(3): 540-546.

21. Thisse, B. and Thisse, C. (2004). Fast release clones: a high throughput expression analysis. ZFIN Direct Data Submission ZFIN ID: ZDB-PUB-040907-1.

22. Thisse, B., Pflumio, S., Fürthauer, M., Loppin, B., Heyer, V., Degrave, A., Woehl, R., Lux, A., Steffan, T., Charbonnier, X.Q. and Thisse, C. (2001). Expression of the zebrafish genome during embryogenesis (NIH R01 RR15402). ZFIN Direct Data submission ZFIN ID: ZDB-PUB-010810-1. 
Please cite this article as: Narayanan and Oates, (2019). Detection of mRNA by Whole Mount in situ Hybridization and DNA Extraction for Genotyping of

23. Thisse, C. and Thisse, B. (2005). High throughput expression analysis of ZF-models consortium clones. ZFIN Direct Data submission ZFIN ID: ZDB-PUB-051025-1.

24. Thisse, C. and Thisse, B. (2008). High-resolution in situ hybridization to whole-mount zebrafish embryos. Nat Protoc 3(1): 59-69.

25. Trivedi, V., Choi, H. M. T., Fraser, S. E. and Pierce, N. A. (2018). Multidimensional quantitative analysis of mRNA expression within intact vertebrate embryos. Development 145(1): dev156869.

26. Wang, F., Flanagan, J., Su, N., Wang, L. C., Bui, S., Nielson, A., Wu, X., Vo, H. T., Ma, X. J. and Luo, Y. (2012). RNAscope: a novel in situ RNA analysis platform for formalin-fixed, paraffin-embedded tissues. J Mol Diagn 14(1): 22-29.

27. Wetmur, J. G. (1976). Hybridization and renaturation kinetics of nucleic acids. Annu Rev Biophys Bioeng 5: 337-361.

28. Wetmur, J. G. and Davidson, N. (1968). Kinetics of renaturation of DNA. J Mol Biol 31(3): 349-370.

29. Yamamoto, A., Amacher, S. L., Kim, S. H., Geissert, D., Kimmel, C. B. and De Robertis, E. M. (1998). Zebrafish paraxial protocadherin is a downstream target of spadetail involved in morphogenesis of gastrula mesoderm. Development 125(17): 3389-3397. 